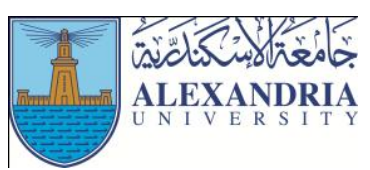

\title{
The Role of the Culture Management of Total Quality on the Organizational Performance of the Sports Federations, the Arab Republic of Egypt
}

\author{
Islam Ghallab Ibrahim Dodo ${ }^{1}$ \\ ${ }^{1}$ Lecturer, Sports Management and Recreation Department, Faculty of Physical Education, Menoufiya University, Egypt
}

\begin{abstract}
The research aims to determine the role of the culture management of total quality on the organizational performance of the sports federations in the Arab Republic of Egypt. The researcher used the descriptive approach with the survey manner because it is suitable for achieving the goals of research. The research community is presented in the managerial and supervisory leaders, employees and beneficiaries of the sports federations in the Arab Republic of Egypt.

The basic research sample consisted of (95) of the individual members of the board of some sports federations, their employees and beneficiaries of the services of the federations. The researcher designed a questionnaire as a tool for collecting data. It was applied on the sample in the period from 16/4/2016 to 16/6/2016. The research has come to a set of results, most notably: The directors of the sports federations in general care about the dissemination and application of all the overall quality in a medium degree. Also, the trends of managers about the level of organizational performance associated with the performance of human resources in general came in a medium degree. There are also statistically significant differences to the dimensions of the whole total quality management $(T Q M)$ represented in the convince of the top management of the sports federations with the culture of total quality management, participating and motivating the employees in the federations. In addition to training and qualifying the employees, making decisions based on the data, the ability to communicate effectively, strategic planning and the continuity of improvement of the level of performance of the sports federations. In light of the findings of the research, a set of recommendations are provided. They aim to establish the concept of the necessity of the adoption of the sports federations and taking into account the culture of total quality management and its dimensions in a comprehensive and meaningful to improve the organizational performance
\end{abstract}

\section{Introduction and Problem of the Research}

$\mathrm{T}$ he Egyptian society is witnessing in the current era a tremendous progress in all public areas in general and especially in the administration field. The Egyptian administration enters the twenty-first century by passing a massive development on both the local and global level due to the new economic and intellectual circumstances that have occurred in the Egyptian society and that creates a whole new world that had not been seen before.

The corporations that rely on the old intellectual underpinnings that believes that the management function is to organize the resources and use them internally to achieve external results they must be quickly responsive to the requirements of competition and to switch to the determination of the desired goals abroad first and then organizing the internal resources and continuously developing it to achieve these goals. $(5: 31)$

Hence the need for serious attention to update the administrative methods that manage these corporations. It is necessary to achieve the specific elements to help them achieve a competitive advantage.

Quality comes to include one of the key elements to achieve a competitive advantage that has a strategic dimension that is necessary to the success of the organizations .(13:77)

The sports bodies like the rest of the other bodies are subjected to the principles and rules of the organization and management. The management in the fields of 
Physical Education has its role in many organizations such as the sports federations.

The sports federations are considered one of the most important bodies that exist in the society and are closely related to the field of Physical Education. This summon the interest in all things for these bodies to get to the best level of service and achievement levels in global and international. (4:23)

\section{Research Objectives}

1- Identifying the administrative reality in the Egyptian sports federations.

2- Identifying the requirements of the activation of TQM in the sports federations.

3- Identifying what obstacle the application of the total quality management in the sports federations.

\section{Research Questions}

1- What is the administrative reality in the Egyptian sports federations?

2- What are the requirements of the activation of total quality management concepts in the sports federations?

3- What are the obstacles to the application of the total quality management in the sports federations?

The field study: (The plan and the producer research)

I) The Research Methodology: The researcher used the descriptive approach with the survey manner with its steps and procedures because of its suitability to achieve the objectives of the research.

\section{II) The Community and the Research Sample:}

A. Research Community: The research community is represented in the managerial and supervisory leaders, employees and beneficiaries of the sports federations in the Arab Republic of Egypt.

B. Sample of the Research: The researcher applied a research questionnaire on an intentional stratified sample of the members of the Board of Directors of some sports federations, employees and the beneficiaries of the federations Services (trainers rulers - players - parents of). This questionnaire is designed to learn about the administrative reality in the federations and to identify the extent of their awareness of the requirements and constraints of the application of TQM is the (Egyptian Handball Federation, Egyptian Federation of Karate and Egyptian Federation of basketball). The number of the research sample was 120 individuals. They represent approximately a percentage of $(7 \%)$ of the original community.

The researcher excluded (25) members of the research sample because they have not completed the answer of all the questionnaire statements or did not pay attention when filling out the forms. Bringing the total sample of actual research (95) individuals, and their distribution (33) members of the Board of Directors, (40) employees in the sports federations, (22) of the beneficiaries of the sports federations. Table 1 shows the description of the distribution of the community and basic research sample.

Table (1)

The Description of the Distribution of the Community and Basic Research Sample

\begin{tabular}{|c|c|c|}
\hline Research Community & Sample of The Research & $\begin{array}{c}\text { The number of } \\
\text { the sample }\end{array}$ \\
\hline $\begin{array}{c}\text { Administrative and supervisory leaders, } \\
\text { employees and beneficiaries of the sports } \\
\text { federations in the Arab Republic of Egypt }\end{array}$ & $\begin{array}{c}\text { A random sample of managerial and supervisory leaders, } \\
\text { employees and beneficiaries of some of the sports } \\
\text { federations in the Arab Republic of Egypt (Handball, } \\
\text { Basketball, Karate Federation) }\end{array}$ & 95 \\
\hline Total & - & 95 \\
\hline
\end{tabular}

III) Data collection tools:

\section{Personal Interview with:}

- Directors of some of the sports federations in the Arab Republic of Egypt.

- Some coaches, referees, players and parents.

Questionnaire:
The researcher used a questionnaire to collect the research data. This questionnaire is prepared by the researcher and he followed these steps in preparing it.

- The theoretical readings of the scientific references and previous studies that are related to the topic of the research.

- Full scan of all the questionnaires which were designed by the previous researchers and that were 
used in previous studies as well as the content of each axis of the axes and every single vocabulary.

Default axes have been identified and their number is (3). Attachment number (2), namely:

- Administrative reality in the Egyptian sports federations.

- The requirements of activating the total quality management concepts in the sports federations.

- Obstacles of the application of the total quality management in the sports federations.

The virtual axes have been introduced on the experts and their number is (5) experts from the sports management professors attachment number (1) so as to add, delete or modify any axis of the axes used in this triple measure of estimation (very important - the average importance - not important). The experts agreed that the first axis is very important by $95 \%$ and the whole experts also agreed that the second axis is very important with a percentage of $93 \%$. The third is important with a percentage of $89 \%$.

Then the researcher formulated a set of statements for each axis. The number of statements reached (34) statement and they are presented to the experts to express their opinion upon them. Attachment No. 3.
The researcher has excluded the statements that the experts agree that they are not important and amending the terms that experts agreed that it is have medium important. The number of words that have been deleted (3) statements. Attachment number (4). (The arbitrators approved the form).

Thus, the researcher reached to the final form of the questionnaire for the research. Attachment number 5 . The number of statements reached (31) statement for all the axes of the final questionnaire (The first axis 8 statements, the second axis 12 statement and the third axis 11 statements). The researcher used a measure of triple assessment in the final questionnaire form and it was (yes - to some extent - no) and is estimated as follows $(2-1-0)$.

The experts agreed on the method of correcting the phrases of the questionnaire. The stability of the form has been calculated by re-applying it after an interval of fifteen days on an exploratory sample of the research community that is based on (5) members of the Board of Directors of some sports federations who are not within the sample of the original study.

Data shown in Table (2) shows that the reliability coefficients for each axis of the axes of the questionnaire is high enabling applying it on the sample of the research.

Table (2)

Stability and Self-Honesty Coefficient (Internal Consistency) To the Questionnaire Form

\begin{tabular}{|c|c|c|c|}
\hline No. & Statement & Stability & $\begin{array}{c}\text { Self- } \\
\text { Honesty }\end{array}$ \\
\hline 1 & Administrative Reality In The Egyptian Sports Federations. & 0.93 & 0.96 \\
\hline 2 & The Requirements Of Activating The Total Quality Management Concepts In The Sports & 0.95 & 0.97 \\
\hline 3 & Federations. & 0.94 & 0.95 \\
\hline
\end{tabular}

1- The questionnaire form is applied on the individuals of the basic research sample through a personal interview in the period from $16 / 4 / 2016$ to $16 / 6 / 2016$.

2- The forms were collected, discharged and analyzed according to the appropriate statistical treatments to the objective of the research.

View the research results and discussing it
Within the limits of methodology and procedures of this research, the researcher presents the findings of his work classified according to the topic of the research which aims to define the role of the culture of the total quality management on the organizational performance of the Sports Federations in the Arab Republic of Egypt in accordance with the objectives as follows 
Table (3)

The Repetition And The Percentage Of The Views Of The Research Sample On The Administrative Reality In The Egyptian Sports Federations ( $N=95)$

\begin{tabular}{|c|c|c|c|c|c|c|c|c|}
\hline \multirow{2}{*}{ No. } & \multirow{2}{*}{ Statement } & \multicolumn{2}{|c|}{ Yes } & \multicolumn{2}{|c|}{ May Be } & \multicolumn{2}{|c|}{ No } & \multirow{2}{*}{ KA2 } \\
\hline & & Repetition & $\%$ & Repetition & $\%$ & Repetition & $\%$ & \\
\hline 1 & $\begin{array}{l}\text { There are standards specifying the } \\
\text { extent to which the achievement of the } \\
\text { objectives of the sports federations. }\end{array}$ & 25 & $20 \%$ & 20 & $25 \%$ & 50 & $55 \%$ & $45.098^{*}$ \\
\hline 2 & $\begin{array}{l}\text { The level of the provided services of } \\
\text { the sports federations commensurate } \\
\text { with the expectations of the } \\
\text { beneficiaries of the federations. }\end{array}$ & 18 & $12 \%$ & 10 & $8 \%$ & 67 & $80 \%$ & $56.068^{*}$ \\
\hline 3 & $\begin{array}{l}\text { The objectives of the sports } \\
\text { federations' management } \\
\text { commensurate with the available } \\
\text { resources. }\end{array}$ & 21 & $22 \%$ & 15 & $17 \%$ & 59 & $62 \%$ & $57.054 *$ \\
\hline 4 & $\begin{array}{l}\text { Officials in the sports federations are } \\
\text { interested to publish the culture of work } \\
\text { according to the requirements of the } \\
\text { beneficiaries. }\end{array}$ & 23 & $19 \%$ & 18 & $24 \%$ & 54 & $57 \%$ & $52.091 *$ \\
\hline 5 & $\begin{array}{l}\text { The employees in the sports federations } \\
\text { participate in the planning and } \\
\text { organization of the work for } \\
\text { federations. }\end{array}$ & 21 & $22 \%$ & 10 & $8 \%$ & 64 & $70 \%$ & $62.073 *$ \\
\hline 6 & $\begin{array}{l}\text { The performance of the sports } \\
\text { federations is consistent with the } \\
\text { current era variables. }\end{array}$ & 5 & $2 \%$ & 12 & $6 \%$ & 78 & $92 \%$ & $77.010 *$ \\
\hline 7 & $\begin{array}{l}\text { The development of the organizational } \\
\text { structure constantly in favor of the } \\
\text { work in the sports federations. }\end{array}$ & 10 & $8 \%$ & 35 & $37 \%$ & 50 & $55 \%$ & $49.019^{*}$ \\
\hline 8 & $\begin{array}{l}\text { The necessary capacities and } \\
\text { capabilities are available for the } \\
\text { conduct of the business efficiently and } \\
\text { effectively in the sports federations. }\end{array}$ & 13 & $9 \%$ & 16 & $20 \%$ & 66 & $71 \%$ & $63.098 *$ \\
\hline
\end{tabular}

* The value of KA2 at a level $0.05=2.92$

The results of table 3 indicated that there is statistically significant differences for the research sample for the benefit of those who answered 'no' in all the statements.

Where it was to reach the administrative reality in the Egyptian sports federations, which indicates the presence of some of the shortcomings by the managers of the sports federations and faces some obstacles. This shows that what happens in reality is general is not proportional to what it should be. This is illustrated as follows:

The objectives of the Sports federations' management are not commensurate with the available resources, the existence of impediments that prevent the optimal planning to achieve the objectives set and the lack of standards that describe the achievement of objectives of the sports federations. The objectives of the sports' activity in the sports federations are not consistent with the variables of the current era. With respect to the organization, the organizational structure is not developed consistently in favor of labor.

The regulations, laws and rules by which the work flow are not reviewed or updated as it is not compatible with the current variables.

The researcher see that this is because of the lack of the interest in the sports federations management to develop its performance in line with the current era variables and the lack of concern for the quality of the services provided by sports federations for the public beneficiaries. This agrees with the opinion of "Mamdouh Mahmud" (2007) (12) where the results of his study indicated that the reality of sports activity management of the university shows that what is happening in reality in general does not suit what should be and this is due to the lack of interest in the 
application of total quality standards. This is consistent with the findings of a number of studies, including the study of "Mona Abdel Moneim" (2005) (13), Samir Ali
(2008) (7), Mahmoud Daoud al-Rubaie (2010) (11) and Adla Matar (2004) (9)

Table (4)

The Repetition And The Percentage Of The Views Of The Research Sample On The Requirements Of Activating The Total Quality Management Concepts In The Sports Federations ( $=95)$

\begin{tabular}{|c|c|c|c|c|c|c|c|c|}
\hline \multirow{2}{*}{ No. } & \multirow{2}{*}{ Statement } & \multicolumn{2}{|l|}{ Yes } & \multicolumn{2}{|c|}{ May Be } & \multicolumn{2}{|l|}{ No } & \multirow{2}{*}{ KA2 } \\
\hline & & Repetition & $\%$ & Repetition & $\%$ & Repetition & $\%$ & \\
\hline 1 & $\begin{array}{l}\text { Continue the update and development to improve the quality } \\
\text { of the sports federations. }\end{array}$ & 90 & $97 \%$ & 4 & $2 \%$ & 1 & $1 \%$ & $89.061 *$ \\
\hline 2 & $\begin{array}{l}\text { Adopting the style of cooperative teamwork among } \\
\text { employees in the sports federations. }\end{array}$ & 84 & $93 \%$ & 8 & $5 \%$ & 3 & $2 \%$ & $87.023 *$ \\
\hline 3 & $\begin{array}{l}\text { Working to overcome the mistakes quickly, leading to reduce } \\
\text { the cost and get the satisfaction of the members and the } \\
\text { employees of the sports federations. }\end{array}$ & 72 & $82 \%$ & 19 & $15 \%$ & 4 & $3 \%$ & $70.039 *$ \\
\hline 4 & $\begin{array}{l}\text { Estimating the cost of the quality and the coverage for all the } \\
\text { business related to the sports federations. }\end{array}$ & 92 & $98 \%$ & 2 & $12 \%$ & 1 & $1 \%$ & $90.067 *$ \\
\hline 5 & $\begin{array}{c}\text { Follow the overall development approach of all areas within } \\
\text { the sports federations such as the objectives and the } \\
\text { organizational structure. }\end{array}$ & 88 & $91 \%$ & 5 & $8 \%$ & 2 & $1 \%$ & $89.045^{*}$ \\
\hline 6 & $\begin{array}{l}\text { Relying on the members that have the ability, talent and } \\
\text { experience. }\end{array}$ & 93 & $98 \%$ & 1 & $1 \%$ & 1 & $1 \%$ & $91.011 *$ \\
\hline 7 & $\begin{array}{l}\text { Improve the capacity and competencies of humanity through } \\
\text { the continuous training in order to invent new methods of } \\
\text { work that able to compete. }\end{array}$ & 91 & $97 \%$ & 3 & $2 \%$ & 1 & $1 \%$ & $89.097 *$ \\
\hline 8 & $\begin{array}{l}\text { The treatment of the employees properly and satisfying their } \\
\text { needs by the style of human relationships at work. }\end{array}$ & 93 & $75 \%$ & 1 & $1 \%$ & 1 & $1 \%$ & $91.011 *$ \\
\hline 9 & $\begin{array}{l}\text { The senior leadership has a development plan for the future of } \\
\text { the sports federations in the coming (3-5) years. }\end{array}$ & 89 & $91 \%$ & 4 & $8 \%$ & 2 & $1 \%$ & $89.009 *$ \\
\hline 10 & $\begin{array}{l}\text { Adding innovations that contribute in improving the } \\
\text { effectiveness of the sports federations. }\end{array}$ & 85 & $89 \%$ & 6 & $8 \%$ & 4 & $3 \%$ & $88.010 *$ \\
\hline 11 & $\begin{array}{l}\text { Setting measurable objectives and the attention to strategic } \\
\text { planning of the sports federations }\end{array}$ & 90 & $72 \%$ & 3 & $2 \%$ & 2 & $1 \%$ & $89.022 *$ \\
\hline 12 & $\begin{array}{l}\text { Establish standards of control and the necessity of using the } \\
\text { tools and the processes of quality and rely on a program to } \\
\text { improve the performance of the sports federations. }\end{array}$ & 77 & $83 \%$ & 11 & $12 \%$ & 7 & $5 \%$ & $74.015^{*}$ \\
\hline
\end{tabular}

\section{$*$ The value of KA2 at a level $0.05=2.92$}

The results of table 4 indicated that there is statistically significant differences for the research sample for the benefit of those who answered 'yes' in all the statements.

It was found that the requirements of the activation of TQM management concepts in the sports federations represented in the continuing to update and develop to improve the quality of the sports federations. In addition to the adoption of the style of cooperative teamwork among the employees in the sport federations and the work to overcome the mistakes quickly, leading to reduce the cost and get the satisfaction of members and employees in the sports federations. In addition to estimating the cost of quality and its coverage for all business related to the sports federations. In addition, following the comprehensive development approach of all areas within the sports federations such as the objectives and organizational structure.

Moreover, relying on the members that have the ability, talent and experience. In addition to improving human capacity and skills through continuous training in order to invent new methods of work to be able to compete. In addition, the treatment of the employees properly and satisfying their needs by the style of human relationships at work. Moreover, the senior leadership has a development plan for the future of the sports federations in the coming years. In addition, Adding innovations that contribute in improving the effectiveness of the sports federations. Moreover, setting measurable objectives and the attention to strategic planning of the sports federations. In addition, 
Establish standards of control and the necessity of using the tools and the processes of quality and rely on a program to improve the performance of the sports federations.

The researcher believes that efforts by the sports federations' management to support the culture of quality and the application of its tactics among the employees in the sports federations will positively come back to the performance of those federations. Thus attract a large sector of the beneficiaries to practice the sports activities and thus expands the sports practice base. This agrees with the study of "Mona Abdel
Moneim "(2005) (13) where the results of her study indicated that the sports federations are considered one of the most important bodies that exist in the society and they are closely related to the field of Physical Education. This summon the interest in all things for these bodies to get to the best level of service, achievement levels and achievements in global and international tournaments and is in line with what a number of studies reached, including a study of "Mamdouh Mahmud" (2007) (12) ", Samir Ali (2008) (7), Mahmoud Daoud al-Rubaie (2010) (11) and Adla Matar (2004) (9).

Table (5)

The Repetition And The Percentage Of The Views Of The Research Samples On The Obstacles Of The Application Of The Total Quality Management In The Sports Federations ( $=95)$

\begin{tabular}{|c|c|c|c|c|c|c|c|c|}
\hline \multirow{2}{*}{ No. } & \multirow{2}{*}{ Statement } & \multicolumn{2}{|c|}{ Yes } & \multicolumn{2}{|c|}{ May Be } & \multicolumn{2}{|l|}{ No } & \multirow{2}{*}{ Total } \\
\hline & & Repetition & $\%$ & Repetition & $\%$ & Repetition & $\%$ & \\
\hline 1 & $\begin{array}{l}\text { Adhere to the prevailing administrative style in the sports } \\
\text { federations and the resistance to change. }\end{array}$ & 55 & $50 \%$ & 22 & $26 \%$ & 18 & $24 \%$ & $53.058 * *$ \\
\hline 2 & $\begin{array}{l}\text { Lack of top management support of the sports federations } \\
\text { to the culture of quality. }\end{array}$ & 82 & $85 \%$ & 8 & $11 \%$ & 5 & $4 \%$ & $80.020 *$ \\
\hline 3 & $\begin{array}{l}\text { Lack of training the employee of the sports federations on } \\
\text { the applications and quality tools. }\end{array}$ & 80 & $86 \%$ & 11 & $8 \%$ & 9 & $6 \%$ & $78.030 *$ \\
\hline 4 & $\begin{array}{l}\text { The fabricating of excuses and causes to confirm the lack } \\
\text { of need for the application of quality in the sports } \\
\text { federations }\end{array}$ & 75 & $83 \%$ & 16 & $15 \%$ & 4 & $2 \%$ & $73.041^{*}$ \\
\hline 5 & $\begin{array}{l}\text { The conviction of the idealism of the current performance } \\
\text { and its ability to satisfy the beneficiaries of the services of } \\
\text { the sports federations. }\end{array}$ & 90 & $97 \%$ & 3 & $2 \%$ & 2 & $1 \%$ & $89.022 *$ \\
\hline 6 & $\begin{array}{l}\text { The individual to make decisions without the involvement } \\
\text { of the employees of the sports federations. }\end{array}$ & 77 & $84 \%$ & 11 & $10 \%$ & 7 & $6 \%$ & $75.062 *$ \\
\hline 7 & $\begin{array}{l}\text { The weakness of the initiative to solve the problems of the } \\
\text { work in the sports federations on time. }\end{array}$ & 66 & $40 \%$ & 50 & $32 \%$ & 44 & $28 \%$ & $64.069 *$ \\
\hline 8 & $\begin{array}{l}\text { The central and the lack of the existence of a database of } \\
\text { the employees and the activities in the sports federations. }\end{array}$ & 90 & $97 \%$ & 4 & $2 \%$ & 1 & $1 \%$ & $89.061^{*}$ \\
\hline 9 & $\begin{array}{l}\text { The weakness of interest to the complaints and } \\
\text { observations of the beneficiaries in terms of the } \\
\text { performance and the service in the sports federations }\end{array}$ & 81 & $89 \%$ & 10 & $9 \%$ & 4 & $2 \%$ & $80.035^{*}$ \\
\hline 10 & The rigid organizational structures in the sports federations. & 90 & $97 \%$ & 3 & $2 \%$ & 2 & $1 \%$ & $89.022 *$ \\
\hline 11 & $\begin{array}{c}\text { The absence of departments or sections of quality } \\
\text { management in the sports federations. }\end{array}$ & 91 & $97 \%$ & 3 & $2 \%$ & 1 & $1 \%$ & $90.072 *$ \\
\hline
\end{tabular}

* The value of KA2 at a level $0.05=2.92$

The results of table 5 indicated that there is statistically significant differences for the research sample for the benefit of those who answered 'yes' in all the statements.

Where it was concluded that the obstacles of the application of the total quality management in the sports federations are represented in the Adhere to the prevailing administrative style in the sports federations and the resistance to change. Moreover, the lack of top management support of the sports federations to the culture of quality. In addition, the Lack of training the employee of the sports federations on the applications and quality tools. In addition, the fabricating of excuses and causes to confirm the lack of need for the application of quality in the sports federations. Moreover, the conviction of the idealism of the current performance and its ability to satisfy the beneficiaries of the services of the sports federations. In addition, the 
individual to make decisions without the involvement of the employees of the sports federations. In addition, the weakness of the initiative to solve the problems of the work in the sports federations on time. In addition, the central and the lack of the existence of a database of the employees and the activities in the sports federations. Moreover, the weakness of interest to the complaints and observations of the beneficiaries in terms of the performance and the service in the sports federations. In addition, the rigid organizational structures in the sports federations. In addition, the absence of departments or sections of quality management in the sports federations.

The researcher believes that the obstacles to the application of TQM in the sports federations is due to several reasons such as the lack of a clear vision of the sports federations to go on the pace and which seeks to the adoption of the philosophy of the total quality management. This philosophy will improve its performance and to develop the quality of its services to the fullest. This agrees with the Study of "Samir Aly" (2008) (7), where the results of his study indicated that the obstacles to the application of the total quality management is presented in the lack of vision and objectives of the sports federation and the lack of supporting the administration to the requirements of their application. And therefore the weakness of the performance level of the sports institutions and federations and this in line with the findings of a number of studies, including the study of "Mona Abdel Moneim (2005) (13), Mamdouh Mahmud" (2007) (12), "Mahmoud Daoud al-Rubaie (2010) (11) and Adla Matar (2004) (9).

\section{Research Findings}

1- The administrative leaders in the sports federations are committed with the total quality management system,. This is an important thing that ensures the continuation of the work of the TQM and that includes a more commitment to the staff by the proposed systems and procedures within the strategy set.

2- There are several requirements to help the sports federations on the success of the application of the total quality management, including the support and the continuous commitment of the senior management to apply the project of the application of the total quality management.

3- There are several obstacles that face the sports federations for the sake of its success when applying the total quality management.

\section{Recommendations}

1- The necessity of the application of the total quality management in the sports federations.

2- The senior management should be interested in the process of continuous development and improvement of the quality and the promotion of the cause of innovation and creativity.

3- The care to satisfy those responsible employees for the provision of the services to the beneficiaries through training and the development of the behavioral skills to improve their ability to deal with the beneficiaries.

4- The attention to the expectations of the beneficiaries of the level of services that are provided by the sports federations

5- The need to establish councils and centers for TQM and ensuring it in the sports federations.

6- spreading the awareness among all the employees with the concept of the importance of the quality in the service.

7- The necessity to use the scientific methods and the available statistical tools to apply the concept of the total quality management.

8- Provide a base of information and data to answer the questions of the beneficiaries.

9- The continuous development and updating the systems, the information technology and the communications

10- Hold continuous meetings, conferences and seminars between the senior management, the employees and the beneficiaries.

\section{References}

\section{First: References in Arabic:}

1- Ahmed Yousef Hamdan 2011: The extent of keeping up with the Faculty of Physical Education and Sports in Al-Aqsa university / University of Gaza to the international quality standards, (A) the magazine of AlAzhar University in Gaza, a series of Humanities, Volume 13, Issue 1

2- Ismail Saud Hanian 2016: the effectiveness of TQM standards in repairing the sports programs and activities at the Deanship of Student Affairs at $\mathrm{Al}$ al-Bayt University, Educational Journal: vol. 30, p. 119, c. 1, June 
3- Joseph Jablonski 1996: the application of total quality management, overview, translation Abdel Fattah Al Nomani) Center of professional expertise for managing, Cairo.

4- Hassan Ahmed El-Shafei2003: Legislation in physical education and sports - laws and regulations administrative regulations of the union and the sports institution - the first part, the fulfillment house for the life of printing and publishing - Alexandria, Egypt

5- Hamza, Ahmed Sero2015 : the requirements of applying the principles of total quality management in some sports Libyan institutions, Ph.D. thesis, Faculty of Physical Education, University of Alexandria

6- Darren Schmidt and Jerome Valjo, 1997.: The director of Total Quality, translated by Mahmoud Abdul Hamid Morsi, prospects dar for the global deployment of creativity and media, Riyadh

7- Samir Ali 2008 : a proposed model for the total quality management of youth and sports office of the province of Hodeida Yemen, Master Thesis, Faculty of Physical Education, Assiut University

8- Ayed Kareem 2014: the degree of the application of the total quality management in the faculties of Physical Education of the Middle Euphrates region as seen by the faculty members, The Arabic magazine to ensure the quality of university education: vol. 7, p. 18.

9- Adla Matar 2004.: the requirements of the application of the total quality management in the Department of Physical Education, Faculty of Basic Education in Kuwait, The scientific journal for the Sciences of Physical Education, No. IV, Tanta, Egypt
10- Philip Ankston1995: the cultural change in the right foundation for TQM. Translated by Abdel Fattah Al Sayed Numan

11- Mahmoud Daoud Al Rubaie 2010: "the development of the Arab sport in the light of the quality management" field Study in Iraq - Master Thesis, unpublished, Faculty of Physical Education, University of Babylon,

12- Mamdouh Mahmud Mohamed Osman2007: "Repairing the sports management at the University of South Valley in light of the elements of the total quality", Master Thesis, Faculty of Physical Education, Assiut University

13- Mona Abdel Moneim 2005: a proposed model for TQM in the Egyptian Table Tennis Federation, PhD thesis, Faculty of Physical Education, Assiut University

\section{Second: References in English:}

14- Dilworth, James1996, Qperation Management, 2ed Ed - New yerk.U.S.A; MC - Qraw - hill

15- Jablonski Joshibhe 2012, mplemintg Mangnt an overview without publisher, san Diego; phe. for, U.S.A ,191, p. 28.

16- Lukhwareni2004, M, Total quality management as a response to educational in school management, (Doctoral Dissertation, University of Pretoria, South Africa)

\section{Third: The International Information Network References}

17- http://www.aptksa.org/vb/showthread.php?t=91

18- http://www.scribd.com/doc/465232/-116 